\title{
Features of Preparing Future Teachers for Work in an Inclusive Educational Environment
}

\author{
Svitlana H. Dubovyk \\ Borys Grinchenko Kyiv University \\ Oleksandra V. Vashchenko \\ Taras Shevchenko National University of Kyiv
}

\author{
Alla M. Moskalenko \\ Taras Shevchenko National University of Kyiv
}

\author{
Valentyn V. Molodychenko \\ Bogdan Khmelnytsky Melitopol State Pedagogical University \\ Nataliia A. Molodychenko \\ Bogdan Khmelnytsky Melitopol State Pedagogical University
}

The purpose of the study: to determine the specifics of preparing future teachers to work in an inclusive educational environment. This study used standard systematic review procedures that include transparent and principled methods for identifying, describing, evaluating, and comparing studies on a specific research issue. A teacher of inclusive education in an educational context represents one of the specific educational resources that, in the context of his specialty, supports, jointly and in the logic of involvement, another student's teachers in defining strategies for pedagogical differentiation and adaptation of curricula, in strengthening learning and in defining various means of motivation, representation and expressiveness. Within the framework of quality educational equity, education systems must not only manage diversity, but also apply a set of appropriate practices and strategies. It is proposed to invest in this area in the curricula of the schools being certified, and tools should be developed at the research level to assess the model that emerges from this review.

Keywords: inclusive education, teacher, training, soft skills, practical knowledge

\section{INTRODUCTION}

An important role in achieving social sustainability can be played by inclusive education where everyone matters, and teachers are the main agents for implementing educational practices that can support the development of each child or young person (Dubovyk et al., 2020). Defect educators from around the world are working hard to empower teachers and prospective teachers to work within the framework of 
inclusive education. Teacher education for inclusive education has become a major focus of action in the context of revitalizing the international policy agenda for inclusive education, resulting in increased student diversity in regular classrooms. After the global paradigm shift from exclusive to inclusive education, the roles and responsibilities of regular education teachers have changed dramatically. Teachers must simultaneously meet the needs of normally developing children and the needs of their peers with special needs in regular classrooms. Thus, inclusive education requires teachers to have a unique set of competencies that have traditionally not been part within their repertoire. Several researchers and peak bodies involved in teaching children with special needs express some of the key competencies needed to effectively teach children with special needs to reap the benefits of learning in regular classrooms.

Such competencies include the knowledge and ability to teach strategies and approaches that meet the needs of all children in regular classrooms (Van der Werf et al., 2021). These skills enable teachers to plan flexible learning and be aware of the reality of differences between and within children, while being able to adapt learning goals, content, and environment to the needs of individuals and the entire class. In accordance with this premise of pedagogical competencies, developed and approved a common core of minimum basic knowledge and skills for entry into professional practice (Rahman, 2018). These standards include student development and individual differences in learning, learning environment, knowledge of curriculum content, assessment, learning planning and strategies, vocational training and practice, and collaboration. Ordinary teachers require a certain level of knowledge in general core skills, although these skills may not be important to them. Similarly, other researchers find important skills for teachers in inclusive classrooms are tutoring, collaborative learning, curriculum change and adaptation, mastery learning and applied behaviour analysis, teaching aids, learning technologies, and supporting children using other children (Van der Werf et al., 2020). Research also suggests that ordinary teachers should use learning strategies such as individual and adaptive learning and activity-based learning to facilitate the learning and learning of children with special needs (Brame, 2019).

Other researchers point out that teachers need competencies in professional knowledge, assessment, teaching techniques, and behaviour management to include children with disabilities in regular classrooms. In addition, teachers need skills in learning strategies such as differentiated learning, multi-level learning, collaboration skills, learning, and activity-based learning to include children with special needs in regular classes (Slot, 2018 a; Askhadullina et al., 2021). Strategies such as collaborative learning and peer learning results in better outcomes for children. For example, single-class learning was created to increase the ability to respond, improve understanding of activities, and minimize problematic behaviour, as well as improve children's behaviour on tasks, math, reading performance, and social interaction of children with disabilities in regular classrooms. Collaborative learning strategies were created to improve intergroup relationships, improve learning, develop problem-solving skills, and upgrading social and academic skills of children with special needs in regular classrooms.

In terms of improving social skills through learning interactions, studies have shown an increase in the frequency, duration, and quality of social interactions among children with disabilities (Lloyd, 2020). Collaboration is also a key competence of teachers in inclusive education. Teachers require, among other things, a collaborative competence that can leverage their own problem-solving and creative thinking when sharing ideas with their peers, as children with special learning needs need a variety of learning approaches. Other researchers point out that teaching and learning requires effective teaching strategies that move away from individual planning associated with individual teaching in special education to instruction adapting the goals and content of learning, as well as the learning environment through interaction with the entire class and at the same time, recognizing the differences among children and among them.

The purpose of the study: to determine the specifics of preparing future teachers to work in an inclusive educational environment.

\section{MATERIALS AND METHODS}

The study used standard systematic review procedures. They consist of transparent and principled methods for identifying, describing, evaluating, and comparing studies that have been devoted to a specific 
research issue. The review is innovative, as it aims to find an answer to the question of the effectiveness and feasibility of interventions in terms of whether they meet the expressed needs of future teachers. A phenomenological case study was conducted using qualitative data collected from face-to-face interviews, a focus group, and a short questionnaire of participants to answer the following questions:

1. What experiences of teacher change are moving from self-directed special education classes to inclusive classes?

2. What impact did this change in classroom placement have on teachers' attitudes and perceptions of students with disabilities and inclusive practices?

The review adopted a conceptual framework of barriers to health and factors contributing to health, in which interventions are seen as aimed at changing or removing obstacles and developing existing mediators. Thus, the experiment consisted of two stages. First, systematic search and validation identified studies that matched the broader survey question. This study was classified to describe the range of existing studies on a systematic map. The second stage was an in-depth examination of a part of this study. The in-depth review included three generalizations:

- performance studies (tests);

- survey data or interview-based research on the experiences and attitudes of inclusive education teachers (attitudes research)

- synthesis of cross-sectional studies, in which test data were compared with data from opinion studies.

Literary search and viewing. Highly sensitive search was performed in a wide range of electronic databases. A number of controlled and free-text time frames for physical activity have been combined with timelines to prepare prospective teachers to work in an inclusive educational environment. Selection of studies for in-depth examination. The research topics presented on the map were discussed at a meeting with government representatives. They identified several policy-related issues and agreed that testing and research views prepare future teachers to work in an inclusive educational environment. The data mining and the assessment of quality aspects. All studies that meet the criteria for inclusion in the in-depth systematic review undergone data extraction and quality assessment using a standardized framework. Data for each study was independently entered by two researchers into a specialized computer database. The trials were considered "methodologically sound" for this review purposes in case of reporting merely studies meeting these criteria were used to determine effectiveness. The results of studies that did not meet these criteria were considered unclear, and their results were not used to justify conclusions about the effectiveness of the intervention. The data synthesis. Three types of analysis were carried out: in the second generalization, the results of each study were considered in connection with the development of measures on the specifics of preparing future teachers to work in an inclusive educational environment.

\section{RESULTS}

The concept of inclusion or inclusive education is paramount and is usually associated with special needs education and students with special needs. This occurs in the context of European schools and the commitment to educate people with disabilities in a regular education system, thus seeking to support the development of educational systems, create schools that can suit all children and young people and to fight isolation. The inclusion implies change. This is a continuous process of developing the learning and participation of all students. This is an ideal that all schools can strive for, but which can never be fully achieved. However, inclusion occurs as soon as the learning development process begins. An inclusive school is a school that is on the movement. This requires restructuring schools to meet the needs of all children and other pedagogy in the classroom and other types of teachers. In this sense, the inclusive teacher, in addition to recognizing differences, uses pedagogy that includes everyone, seeking to provide differentiated learning, and he or she organizes activities and interactions in a way each of them often faces enrichment situations according to their personal characteristics and needs.

By promoting the development of various strategies, the teacher becomes a facilitator, a true builder of learning environments promoting personal, cultural and social development. He or she will have to develop 
and manage these environments by being flexible enough to deal with the unexpected, uncertainty, expression of feelings, doubts, and fears of those who grow up as well as those who learn. The teacher must continue to shape, discover, reflect, adapt, identify, and imagine new ways of doing things more appropriate and closer to the realities facing on a daily basis. Pedagogical differentiation appears as a way to respect differences, providing everyone with the same opportunities (Bleses et al., 2018). To be able to differentiate, you must not be indifferent to the differences. For classroom teaching, it is assumed that all students can learn, but on time and in their own way; that is, everyone learns certain knowledge according to their own characteristics, which derive from their own knowledge and the habit of thinking and acting. Therefore, attention to individual differences, regardless of their origin, in an inclusive school requires an open and flexible curriculum that can meet the overall needs of the entire school population. It is necessary to differentiate, adapt and individualize the curriculum in accordance with the needs and characteristics of each student. All students should have the same rights and opportunities, including the right to difference and education adapted to their needs.

These fundamental values along with the areas of competence associated with them, comprises three elements: attitude (knowing how to be and how to live together), knowledge (ability to know) and capability (ability to do). A certain attitude or belief requires a certain knowledge or level of understanding, and then the ability to implement this knowledge in a practical situation. For each specific area of competence, the basic attitudes, knowledge, and skills that support them are presented. The teacher's skills and profile have changed and, if in the recent past, he was a teacher with a set of knowledge and skills that in schools contributed to the integration of students (Bjørnestad and Os, 2018). Today, with the introduction of a new educational paradigm for inclusion, this vision has changed. Thus, he began to direct his activities to all students with special needs, whether they have disabilities. For the first time, its competence was legally organized in five areas: critical analysis, intervention, training, supervision, and evaluation. However, according to some studies, this organization is not very clear, since each school treats it differently. In this sense, and for better clarification, it is recommended to consider the competence profile of an inclusive education teacher in terms of establishing a bridge between the school that exists and the school that one would like to have. Thus, it points to a set of premises that define teachers of inclusive education as a collegial element of the school, teachers must collaborate with their peers while learning and teaching, and above all reflecting on what are the best models, frameworks and materials that ensure quality education for all students. An inclusive education teacher must also be:

- a teacher who, within the pedagogical structure, is responsible for collecting, producing and sharing information relevant to the education of all students;

- a professional who owns intervention models that enable the school to understand, plan, execute, and evaluate inclusive pedagogical intervention models;

- a professional who is able to formulate the internal and external services of the school in a harmonious and coordinated way to achieve the best possible results.

In this profile, the teacher of inclusive education is a professional with specialized training in one of his fields, a professional with scientific and practical knowledge in his field, which will allow him to intervene directly in specific knowledge. Thus, in order for each student to progress in their studies, they will essentially be a consultant, collaborator, supervisor, co-author and intermediary of practices that lead to the success and quality of teaching. In short, he will be an inclusive teacher, as everyone should be, but specialized, contributing to the creation of a high-quality school where everyone learns according to their characteristics and abilities. To summarize, he will be an inclusive teacher who, in addition to his pedagogical and teaching skills, also known as hard skills, must have skills in a set of personal and social skills conducive to effective action. These skills are called soft skills.

The concept of soft skills has been considered in human resources, management, psychology, education, and the social sciences in general. However, some consensus has been found around the definition as a set of technical, methodological, and practical skills that are dynamically activated and displayed in execution (Van der Werf et al., 2019; Abdul-Rahman Al-Malah et al., 2020; Senne et al., 2020; Shcherban et al., 2021). Based on the concept of competence, it provides for the operationalization of a set of knowledge and attitudes in a specific situation in order to achieve specific results. In turn, the concept of 
soft implies the opposite of hard, hard skills related to technical skills, and soft skills related to personal and social skills. The concept of transferred skills is intertwined with the concept of soft skills, which are defined as "personality traits, goals, motivations and preferences that are valued in the labour market, in school and in many other areas" (Bleses et al., 2018). Personal skills allow people to manage their personal qualities, improve performance, and maintain interpersonal relationships with others.

As for soft skills, it should be noted that researchers consider the development of their cross-cutting skills relevant, and this area should be considered among the priorities of the National Learning Policy, valued both in school and in the labour market, and in general in social interaction. This relevance is justified by the fact that the degree of development of this type of skill implies productivity, since they complement technical skills. Thus, it can be concluded that the challenges of a teaching career today can be more easily overcome by teachers with soft skills, in addition to the technical skills that are inherent in them. It is advisable that, in addition to promoting the development of these competencies by teachers, they should also be developed by students, since their proficiency leads to an improvement in the overall teaching and learning process (Slot, $2018 \mathrm{~b}$ ). This suggestion is justified by the fact that these skills are acquired mainly through social-emotional dynamics, hence the relevance of special education teachers developing soft skills during the learning period, as a way to give them a significant pedagogical presence in the educational community (Arslan, 2018).

Empirical evidence also points to the fact that teachers' pedagogical abilities are linked to their crosssectional competencies, with those who possess them proving to be more pedagogically effective than those who possess only theoretical knowledge (Dubovyk et al., 2020). Therefore, it can be concluded that the challenges of a teaching career today can be more easily overcome by teachers skilled in soft skills, in addition to the technical skills that are inherent in it, thus being able to effectively manage their daily tasks in a complex context, such as today, presented to special education. For all these reasons, the following question was identified: what soft skills do special education teachers need most to succeed in their professional activities? Thus, this study aims to identify and describe the soft skills of special education teachers.

\section{DISCUSSION}

The decline in the number of database publications (Scopus, Web of Science) related to the soft skills of special education teachers in the inclusion process reveals the lack of research in this area and, as a result, the need for research in this area. The profile of a teacher-defectologist should, in addition to the technical skills inherent in his special group, include soft skills. In this sense, the study identified a model of six soft skills that are now described and discussed. Therefore, in accordance with the above results and in response to the presented research question, it was found that some soft skills occupy an appropriate place in the training of speech pathologists, highlighting effective communication, collaboration and reflexivity. These results are consistent with the results of scientific research (Baustad and Bjørnestad, 2020) confirming the importance of soft skills and the need for their placement for success in professional life, as well as that of teachers, especially during primary education and throughout life. Thus, it can be concluded that soft skills are crucial in accessing and performing the functions of special education teachers.

To guide learning and learning processes, all education naturally presupposes competence in effective communication, sharing, exchanging ideas, exchanging information and interacting. Most peer-reviewed articles have explicit references to effective communication. For example, it is argued that teacher training institutions should find strategies to enable all novice teachers to be effective teachers, be persistent, open-

minded, reflective, and therefore good communicators. Therefore, this soft skill involves a diverse set of factors, as it is a complex phenomenon. A person communicating at different levels includes a diverse set of factors that allow them to express what they think, feel and want, choosing a set of attitudes that are appropriate for each situation, according to the place and moment, and all this is fundamental in the context of inclusive education, where a special education teacher acts. Thus, it is concluded that in educational interaction, effective communication is important for achieving the goals of special education (Slot et al., 2018). 
In addition to effective communication, special education involves collaboration, which consists of planning, action, and evaluation in a team (Somma and Bennett, 2020). Some of the articles analysed have explicit references to collaboration, which is consistent with those who claim that teamwork is important for inclusive education. For this reason, educators need to improve their ability to collaborate, which is the ability to operationalize knowledge, attitudes, and skills to work together to achieve a common goal by maximizing each person's potential in a long-term and balanced way. Promoting collaboration in schools means highlighting the explicit intention of each of them to add value to collaboration by contributing to something else. Naturally, this type of action is increasingly used because it is properly defined in educational projects of educational institutions. So, these are important soft skills in the preparation and work of teachers-defectologists. Reflection is also important in special education, as it is necessary to reformulate actions in order to analyse, plan activities, and deal constructively with uncertainty and unpredictability. To achieve success in inclusive education, the use of reflective thinking is also envisaged, as described in the literature. In this sense, reflexive activity is widely used in teacher training programs. These measures are constantly evolving in order to plan for the unforeseen circumstances of daily learning (Mierendorff et al., 2018).

This ability, according to the aforementioned authors, is manifested in the ability to ask and doubt, to conduct a dialogue and to criticize. In this sense, educational actions require systematic, rigorous and strategic understanding of emerging problems and appropriate plans for their sustainable solution. It is the unpredictability of educational situations that requires the promotion of these reflexive habits as a way of high-quality education for children, young people and adults with special needs. So when someone joins an educational team, they even need to provide hands-on knowledge of methods and techniques to be creative and reflective in the context of learning activities. Special education involves the competence of sustainability. A teacher-defectologist needs the competence of resilience to overcome the difficulties that his profession inevitably creates. This can be defined as the ability to use knowledge, attitudes, and skills to prevent, minimize, or overcome the harmful effects of crises and adversity. Thus, a persistent teacher, when faced with a stressful or unfavourable situation, can use his personal resources, assuming behaviours that help him succeed in this circumstance (Üver et al., 2018).

Successful inclusive teachers also exhibit behaviours characterized by self-efficacy. Self-efficacy is associated with beliefs about the ability to have self-control over individual behaviours and events that affect life. It is this competence that facilitates decision-making in difficult situations, as it allows you to think and evaluate circumstances, have self-determination and flexibility to effectively achieve previously defined goals. These findings are consistent with research indicating that there is strong evidence that teacher's self-efficacy for each child is an important factor to consider in the context of inclusive education. Therefore, this soft skill will be necessary in the professional activity of a teacher-defectologist. This study looked at a group of teachers who were underrepresented in the literature. The study only briefly examined the attitudes and beliefs about inclusion of defectologist teachers working in self-taught classrooms, and it is not known for sure whether defectologist teachers hold positive beliefs about inclusion. However, research on teacher change in general indicates that a positive experience, such as a student with an exception that achieves a concept much larger than the teacher imagined, or develops friendships with classmates, can change the teaching beliefs of excluded students in inclusive classrooms. (Dewsbury and Brame, 2019).

The teachers in the current study, all of whom identified in their anecdotes, moments when their thoughts about student segregation with exceptions shifted from a positive environment to doubts that there should be a better alternative. When they answered specific questions about their teaching practices and personal beliefs, and described their diverse experiences throughout their teaching career, the process of their change became apparent. Analysis of the changes experienced by these teachers has led to the development of visual representation, supported by both previous field research and current results. Literature on changing teachers. Representation combines the way teachers in this study defined their own process of change in how they describe their perceptions, attitudes of others, and their experiences with students in their classrooms (Press and Woodrow, 2018). The researchers discussed a model in which inclusive classes should exhibit five characteristics, including: heterogeneous grouping, a sense of 
belonging, collaborative activities with individual outcomes, the use of an environment in which all people attend, and a balanced educational experience. The basic concepts of this model are consistent with what has been discussed less systematically in the recent literature (Van Huizen et al., 2019). The data collected in the current study is naturally sorted into a continuum of changes specifically related to the experience of these inclusive teachers, which can be linked to the model. While teachers discussed their experiences, five elements emerged: environment, heterogeneous grouping, balanced learning experience, shared experiences with individual outcomes, and belonging at different times throughout their careers.

Teachers in this study discussed the use of environments at the beginning of their attempts to integrate students with disabilities into general education classes. Heterogeneous grouping, where students match the age of peers with different levels of ability, and a balanced learning experience are the desires that these teachers had for their students in independent classes. They sought to gain access to these capabilities only to face numerous challenges and obstacles embedded in the separate system they were working on (Leseman and Slot, 2020). It wasn't until they started developing an inclusive classroom environment as public teachers that they were able to fully differentiate and create shared experiences with individual outcomes. Finally, a sense of belonging for all students remains the most desirable outcome. The teachers in this study identified a complete understanding of the overall picture of inclusion of people based on fundamental human rights through a critical lens, where barriers created by systems are challenged and replaced by non-exclusive structures. Professional readiness and teaching practices, as well as the ability to access authentic experiences, including students with disabilities, are also included in this discussion.

An inclusive caregiver change continuum elaborates and provides insight into how someone moves in the caregiver change process by developing inclusive classes. This visual representation describes the experience of ten caregiver participants, which begins when the caregiver decides to understand, evaluate, and adopt inclusive pedagogy. Whenever initiatives such as inclusion come to the fore in programming and planning in schools, the process of change becomes apparent and expected (Pavolini and Van Lancker, 2018). This change is deeply rooted in the beliefs and practices of educators. To move on to this experience of change in inclusive pedagogy, a person must make a concerted decision to try an inclusive practice in their classroom, along with the appropriate climate and support of the school leader. Since it was found that changes occur at different rates over time, the results of this study support this concept of change as a process. All teachers who participated in this study found changes in their views on education and inclusion of students with exceptions to some extent occurring throughout their teaching careers, first in self-taught special education classes and now in inclusive classes. While many teachers identified their turning point as one that occurred before they moved to an inclusive classroom, it is possible that their views and perceptions of inclusion were also influenced by their involvement in the transition to inclusive practice on a general level. At the time of data collection, the culture of their schools has changed depending on the school board's general attitude to learning and the inclusion of students with exceptions (Üver, 2019).

Special education also includes empathy competence. Among the articles analysed in this review, the focus is on this topic. The ability to actively listen to learners is also important in inclusive education (Dubovyk et al., 2020). Empathy is the ability to listen to perceive the other person's thoughts, feelings, and intentions, providing an adequate understanding of the situation being expressed and encouraging similar future situations (Van Huizen and Plantenga, 2018). Thus, teachers, especially those who receive special education, need to develop this communication skill, improving not only verbal communication, but also nonverbal communication. This accompanies the exchange of information, looks, gestures, and smiles, which makes the other person feel understood, accepted, and encouraged. Thus, according to the above, it can be argued that the paper has an answer to the research question, since six soft skills necessary for special education teachers to succeed were identified. It should also be noted that this review has certain limitations, in particular the existence of a small number of scientific publications on this topic. Most articles focus on empirical work aimed at students, not teachers. Moreover, the research methodology, an exhaustive analysis, was mostly descriptive, but could be accompanied by a meta-analysis. 


\section{CONCLUSIONS}

From the analysis of the articles and according to the soft skills chosen - resilience, flexibility, empathy, teamwork, self-efficacy, and effective communication - it was concluded that although they emerge in isolation, effective communication, teamwork and reflexivity predominate. Due to the lack of literature in this area and in several articles found, no theoretical models have been tested. Thus, there are certain gaps in this area not only at the level of scientific production, but also at the level of specialized training of these teachers. As described in the literature, proper training of professionals for these new roles and responsibilities requires the introduction of a new learning model, as the challenges of a teaching career today can be more easily overcome with soft skills, in addition to the technical capabilities inherent in it.

The teacher-defectologist plays a leading role, for which they need not only innovative educational and didactic practices and scientific knowledge inherent in their special group, but also a set of soft skills that can contribute to inclusive education. In this sense, in a truly inclusive school, its actors act with the development of all students in mind, and without the skills mentioned above, their performance is limited, and the entire educational system is also impoverished. In the current environment, updating the profile of special education teachers increasingly requires the acquisition of cross-cutting competencies to enable them to respond effectively to the challenges of schools, which by definition should be comprehensive, promoting equality, evaluating diversity, teamwork, reflexivity and sustainability.

\section{REFERENCES}

Abdul-Rahman Al-Malah, D.K., Khudair Jinah, H.H., \& Salim ALRikabi, H.T. (2020). Enhancement of educational services by using the internet of things applications for talent and intelligent schools. Periodicals of Engineering and Natural Sciences, 8(4), 2358-2366.

Arslan, S. (2018). Social emotional learning and self-regulation: The mediating role of critical thinking. International Journal of Learning and Change, 10(2), 101-112.

Askhadullina, N.N., Vishnyakova, I.V., Aminova, G.A., Safargaliev, E.R., \& Hamatgaleeva, G.A. (2021). The search of alternative ways for professional training of future teachers to the innovationrelated risks. International Journal of Learning and Change, 13(6), 674-685.

Baustad, G., \& Bjørnestad, E. 2020. Everyday interactions between staff and children aged 1-5 in Norwegian ECEC. Retrieved from https://www.tandfonline.com/doi/full/10.1080/09575146.2020.1819207

Bjørnestad, E., \& Os, E. (2018). Quality in Norwegian childcare for toddlers using ITERS-R. European Early Childhood Education Research Journal, 26(1), 111-127.

Bleses, D., Højen, A., Justice, L.M., Dale, P.S., Dybdal, L., Piasta, S.B., . . Haghish, E.F. (2018). The effectiveness of a large-scale language and preliteracy intervention: The SPELL randomizedcontrolled trail in Denmark. Child Development, 89(4), e342-e363.

Brame, C.J. (2019). Science teaching essentials: Short guides to good practice. San Diego: Academic Press.

Dewsbury, B., \& Brame, C.J. (2019). Inclusive teaching. Retrieved from https://www.lifescied.org/doi/pdf/10.1187/cbe.19-01-0021

Dubovyk, S.H., Lyurina, T.I., Molodychenko, V.V., Molodychenko, N.A., \& Moskalenko, A.M. (2020). Preparing future teachers for work in an inclusive educational environment. International Journal of Psychosocial Rehabilitation, 24(8), 6805-6822.

Leseman, P.P.M., \& Slot, P.L. (2020). Universal versus targeted approaches to prevent early education gaps: The Netherlands as case in point. Zeitschrift für Erziehungswissenschaft, 23, 485-507.

Lloyd, E. (2020). Towards a public ECEC system. In C. Cameron \& P. Moss (Eds.), Transforming early childhood in England: Towards a democratic education (pp. 83-99). London: UCL Press.

Mierendorff, J., Ernst, T., \& Mader, M. (2018). Embedded internationalisation and privilege in German early years provision. In C. Maxwell, U. Deppe, H-H. Krüger, \& W. Helsper (Eds.), Elite Education and Internationalisation (pp. 121-137). Cham: Palgrave MacMillan. 
Pavolini, E., \& Van Lancker, W. (2018). The Matthew effect in childcare use: A matter of policies or preferences? Journal of European Public Policy, 25(6), 878-893.

Press, F., \& Woodrow, C. (2018). Marketisation, elite education and internationalisation in Australian early childhood education and care. In C. Maxwell, U. Deppe, H-H. Krüger, \& W. Helsper (Eds.), Elite Education and Internationalisation (pp. 139-159). Cham: Palgrave MacMillan.

Rahman, A. (2018). An effective teaching plan to introduce professional and practice-based education at tertiary institution. International Journal of Learning and Change, 10(3), 185-197.

Senne, F., Portilho, L., Storino, F., \& Barbosa, A. (2020). Unequal inclusion: An analysis of the trajectory of inequalities in access, use and appropriation of the internet in Brazil. Revista De Direito, Estado e Telecomunicacoes, 12(2), 187-211.

Shcherban, T.D., Bretsko, I.I., \& Varha, V.S. (2021). Psychological and pedagogical features of training future psychologists. Scientific Bulletin of Mukachevo State University. Series "Pedagogy and Psychology”, 7(3), 70-77.

Slot, P.L. (2018a). Early childhood education and care in the Netherlands: A shift towards an integrated system aimed at enhancing children's development and learning. In S. Garvis, S. Philipson, \& H. Harju-Luukainnen (Eds.), International perspectives on early childhood education and care (pp. 213-226). London: Routledge.

Slot, P.L. (2018b). Structural characteristics and process quality in early childhood education and care: A literature review. Retrieved from https://www.oecd-ilibrary.org/education/structuralcharacteristics-and-process-quality-in-early-childhood-education-and-care_edaf3793-en

Slot, P.L., Bleses, D., Justice, L.M., Markussen-Brown, J., \& Højen, A. (2018). Structural and process quality of Danish preschools: Direct and indirect associations with children's growth in language and preliteracy skills. Early Education and Development, 29(4), 581-602.

Somma, M., \& Bennett, S. (2020). Inclusive education and pedagogical change: Experiences from the front lines. International Journal of Educational Methodology, 6(2), 285-295.

Ünver, Ö. (2019). Accessibility and inclusiveness of early childhood education and care across Europe: Policies and experiences. Leuven: Catholic University of Leuven.

Ünver, Ö., Bircan, T., \& Nicaise, I. (2018). Perceived accessibility of childcare in Europe: A crosscountry multilevel study. Retrieved from https://ijccep.springeropen.com/track/pdf/10.1186/s40723-018-0044-3.pdf

Van der Werf, W., Slot, P., Kenis, P., \& Leseman, P. (2019). Gevolgen van marktdifferentiatie voor diversiteit, inclusie en kansengelijkheid in kindercentra, een vergelijkende casestudy. Sociologie, 14(1), 1-24. [in Dutch].

Van der Werf, W.M., Slot, P.L., Kenis, P., \& Leseman, P.P.M. (2020). Hybrid organizations in the privatized and harmonized Dutch ECEC system: Relations with quality of education and care. Early Childhood Research Quarterly, 53(4), 136-150.

Van der Werf, W.M., Slot, P.L., Kenis, P.N., \& Leseman, P.P.M. (2021). Inclusive practice and quality of education and care in the Dutch hybrid early childhood education and care system. International Journal of Child Care and Education Policy, 15, Article number 2.

Van Huizen, T., \& Plantenga, J. (2018). Do children benefit from universal early childhood education and care? A meta-analysis of evidence from natural experiments. Economics of Education Review, 66, 206-222.

Van Huizen, T.M., Dumhs, E., \& Plantenga, J. (2019). The costs and benefits of investing in universal preschool: Evidence from a Spanish reform. Child Development, 90(3), e386-e406. 